Running Head: Prediction of long-term relapse in abstinent smokers

Implicit attitudes towards smoking predict long-term relapse in abstinent smokers

\author{
Adriaan Spruyt ${ }^{1,2}$, Valentine Lemaigre ${ }^{3}$, Bihiyga Salhi ${ }^{4}$, Dinska Van Gucht ${ }^{2}$, Helen Tibboel ${ }^{1}$, Bram Van \\ Bockstaele $^{5}$, Jan De Houwer ${ }^{1}$, Jan Van Meerbeeck ${ }^{1,6}$, \\ \& Kristiaan Nackaerts ${ }^{2,3}$
}

\author{
Ghent University ${ }^{1}$ \\ Catholic University of Leuven ${ }^{2}$ \\ Gasthuisberg University Hospital ${ }^{3}$ \\ Ghent University Hospital ${ }^{4}$ \\ University of Amsterdam ${ }^{5}$ \\ Antwerp University Hospital ${ }^{6}$
}

\author{
Adriaan Spruyt \\ Department of Psychology \\ Ghent University \\ Henri Dunantlaan 2 \\ B-9000 Ghent, Belgium \\ TEL: ++32-9-264-64-44 \\ FAX: ++32-9-264-64-89
}

E-mail: Adriaan.Spruyt@UGent.be 


\begin{abstract}
Rationale. It has previously been argued that implicit attitudes towards substance-related cues drive addictive behavior. Nevertheless, it remains an open question whether behavioral markers of implicit attitude activation can be used to predict long-term relapse.

Objectives. The main objective of this study was to examine the relationship between implicit attitudes towards smoking-related cues and long-term relapse in abstaining smokers.

Methods. Implicit attitudes towards smoking-related cues were assessed by means of the Implicit Association Test (IAT) and the Evaluative Priming Task (EPT). Both measures were completed by a group of smokers who volunteered to quit smoking (Patient Group) and a group of non-smokers (Control Group). Participants in the Patient Group completed these measures twice: once prior to smoking cessation and once after smoking cessation. Relapse was assessed by means of short telephone survey, six months after completion of the second test session.

Results. EPT scores obtained prior to smoking cessation were related to long-term relapse and correlated with self-reported nicotine dependence as well as daily cigarette consumption. In contrast, none of the behavioral outcome measures were found to correlate with the IAT scores.

Conclusions. These findings corroborate the idea that implicit attitudes towards substancerelated cues are critically involved in long-term relapse. A potential explanation for the divergent findings obtained with the IAT and EPT is provided.
\end{abstract}

Keywords: implicit attitudes; evaluative priming, implicit association; nicotine; relapse; picturepicture naming task; extra-personal associations 


\section{Implicit attitudes towards smoking predict long-term relapse in abstinent smokers}

Relapse in abstaining substance-dependent patients is typically (very) high (e.g., Moos \& Moos, 2006; Sheffer et al., 2012). It should therefore come as no surprise that addiction researchers have invested a great deal of effort in identifying the psychological processes that bring about renewed drug use after successful treatment. If anything, this line of research has shown that drug relapse is caused by a complex interplay of various factors, including inter-individual differences in coping strategies (e.g., Gossop, Stewart, Browne, \& Marsden, 2002), impulsiveness (e.g., Fox, Bergquist, Gu, \& Sinha, 2010), the propensity to delay reward (e.g., Sheffer et al., 2012), attentional bias to substance-related cues (e.g., Powell, Dawkins, West, Powell, \& Pickering, 2010), working memory capacity (e.g., Patterson et al., 2010), and craving (e.g., Wise, 1988).

There is also evidence showing that relapse is dependent upon automatically activated attitudes towards substance-related cues (hereafter referred to as implicit attitudes, see De Houwer, TeigeMocigemba, Spruyt, \& Moors, 2009). As an example, consider the findings of Marhe, Waters, van de Wetering, and Franken (2013), who used the Implicit Association Test (hereafter referred to as IAT; see Greenwald, McGhee, \& Schwartz, 1998) to capture implicit attitudes towards heroin and cocaine in abstaining drug-dependent patients. Results showed that IAT scores obtained during episodes of increased temptation (in contrast to IAT scores obtained at randomly selected moments) were much more positive in drug-dependent patients who relapsed within nine days of treatment as compared to patients who remained abstinent. This finding is further corroborated by a large number of nonclinical studies in which measures of implicit attitudes towards drugs were found to correlate with various aspects of addictive behavior (for a meta-analysis, see Rooke, Hine, \& Thorsteinsson, 2008). In the context of alcohol addiction, for example, Wiers and colleagues demonstrated repeatedly that an IAT measure of the implicit attitude towards alcohol correlates with self-reported alcohol use (e.g., Houben, Nosek, \& Wiers, 2010; Wiers, van Woerden, Smulders, \& de Jong, 2002). Likewise, Descheemaeker, Spruyt, and Hermans (2014) were able to predict beer consumption during a bogus taste test on the 
basis of the implicit attitude towards beer as measured by the Evaluative Priming Task (hereafter referred to as EPT, see Fazio, Jackson, Dunton, \& Williams, 1995).

The observation that implicit attitudes towards substance-related stimuli can drive addictive behavior is in line with recent two-process models of addiction (e.g., Deutsch \& Strack, 2006; Strack \& Deutsch, 2004; Wiers \& Stracy, 2006). According to these models, addictive behavior is governed by two semi-independent systems: an 'impulsive system', in which the affective-motivational significance of substance-related stimuli and associated behavioral schemata become activated in an automatic fashion, and a 'reflective system' in which knowledge about the values and probabilities of different behavioral consequences is weighed and integrated in a non-automatic fashion. Crucially, the operating conditions of both systems are assumed to be quite different. Whereas the operation of the reflective system is assumed to require a high amount of cognitive capacity, the opposite is true for the impulsive system (Strack \& Deutsch, 2004). Two-process models of addiction therefore predict that the impulsive system will exert primary control over behavior under conditions of reduced motivation and/or opportunity to engage in reflective processing (see also Fazio \& Towles-Schwen, 1999). Crucially, the capacity to engage in reflective processing is assumed to vary as a function stable differences between individuals (e.g., Farris, Ostafin, \& Palfai, 2010; Lindgren, Neighbors, Westgate, \& Salemink, 2014; Thush et al., 2008; Spruyt et al., 2013; but see Pieters, Burk, Van der Vorst, Wiers, \& Engels, 2012) as well as temporary factors such as cognitive load, fatigue, and stress (Wiers, Ames, Hofmann, Krank, \& Stacy, 2010). Accordingly, two-process models of addiction can readily explain the observations that (a) it is difficult to abstain from substance abuse and (b) relapse rates in abstaining patients are typically very high.

Nevertheless, only a few attempts have been made to document the relationship between implicit attitudes towards drug-related cues and relapse to dependence. Moreover, in each of these studies, relapse was monitored during a relatively brief follow-up period (e.g., Marhe et al., 2013). It thus remains an open question whether measures of implicit attitudes towards substance-related cues can be useful to predict long-term relapse in abstaining substance-dependent patients. To shed light on 
this issue, we examined implicit attitudes towards smoking-related cues in a large sample of smokers who had already signed up for participation in a smoking cessation program (hereafter referred to as the Patient Group). Both the IAT and the EPT were used to capture the implicit attitude towards smoking. We asked participants to complete the implicit attitude measures immediately following the first session of the smoking cessation program (i.e., prior to their attempt to quit smoking). Smokers who actually managed to quit smoking were asked to complete the implicit attitude measures for a second time between four and eight days after smoking cessation. Six months later, relapse was assessed by means of short telephone survey.

Although the relationship between relapse and measures of implicit attitude activation towards smoking was the prime focus of the present study, we also wanted to address a number of additional research questions. First, we wanted to compare the predictive validity and reliability of the IAT and EPT. Although both measures are referred to as 'implicit attitude measures', the underlying mechanisms that drive performance in these tasks are known to be quite different (see Conrey, Sherman, Gawronski, Hugenberg, \& Groom, 2005; Klauer, Voss, Schmitz, \& Teige-Mocigemba, 2007; Spruyt, Hermans, De Houwer, Vandromme, \& Eelen, 2007). Unlike the EPT, for example, the IAT is sensitive to salience asymmetries (e.g., Rothermund \& Wentura, 2004), recoding processes (e.g., Rothermund, TeigeMocigemba, Gast, \& Wentura, 2009), and automatically activated extra-personal associations (Karpinski \& Hilton, 2001). In addition, it has been argued that the EPT allows for a measurement of implicit attitudes at the exemplar level (i.e., the individual stimuli that are used in the task) whereas the IAT is more suited to capture implicit attitudes at a category level (De Houwer et al., 2009). It is therefore important to compare the added value of the IAT and the EPT directly, an endeavor that has yet to be undertaken in the context of addiction in general and relapse in particular.

Second, we wanted to examine whether the predictive validity of implicit attitude measures is dependent upon attentional control. Several studies have shown that substance-dependent patients are characterized by an attentional orienting response towards drug-related stimuli (Fadardi \& Cox, 2009; Field \& Cox, 2008; Townshend \& Duka, 2001). We therefore reasoned that the implicit attitude towards 
smoking may be more likely to affect addictive behavior in persons who have difficulty controlling the attention-grabbing power of smoking-related stimuli (Wiers et al., 2010; Farris et al., 2010). The more a smoker tends to attend to smoking-related stimuli, the more likely this person will be influenced by his/her implicit attitude towards those stimuli. Accordingly, we also administered the Attentional Control Scale (hereafter referred to as $A C S$ ), a measure of individual differences in the ability to focus perceptual attention, switch attention between tasks, and flexibly control thought (Derryberry, 2002; Derryberry \& Reed, 2002). In line with Farris et al. (2010), we expected the predictive validity of the IAT and the EPT to be more pronounced in abstaining nicotine-dependent patients who score low on the ACS than in nicotine-dependent patients who score high on the ACS (see also Wiers et al., 2010).

Finally, we wanted to examine whether smokers who are committed to quit smoking exhibit different implicit attitudes towards smoking-related cues as compared to non-smokers. Whereas previous research has invested a great deal of effort in comparing implicit attitudes toward smokingrelated cues in smokers and non-smokers (e.g., Payne, McClernon, \& Dobbins, 2007; Swanson, Rudman, \& Greenwald, 2001), very little is known about implicit attitudes towards smoking-related cues in the subgroup of smokers who are committed to quit smoking. There are some reasons to suspect, however, that implicit attitudes towards smoking-related cues might be quite negative in individuals who are committed to abstinence. In the context of alcohol addiction, for example, Spruyt et al. (2013) demonstrated that abstaining alcohol-dependent patients are characterized by a strong automatic tendency to avoid alcohol-related cues. Likewise, Noel et al. (2006) observed that abstaining alcoholdependent patients can develop an attentional bias away from alcohol-related stimuli. It might thus be hypothesized that smokers who are committed to abstinence might exhibit a more negative implicit attitude towards smoking-related cues as compared to non-smokers. To verify this prediction, we assessed implicit attitudes toward smoking-related stimuli both in a sample of smokers who were committed to quit smoking and a sample of 30 non-smokers (hereafter referred to as the Control Group). 


\section{Method}

\section{Participants and design}

Participants were a convenience sample of 78 smokers ( 48 men) and 30 controls (13 men). Participants from the Patient Group were either recruited at the smoking cessation clinic of Gasthuisberg University Hospital, Leuven, Belgium ( $n=57)$ or Ghent University Hospital, Ghent, Belgium $(n=21)$. They were asked to participate after they had already volunteered to enter a smoking cessation program and were offered $€ 30$ in exchange for their participation. Payment was contingent, however, upon completion of two test sessions: once prior to smoking cessation and once after smoking cessation. At the first test session, participants in the Patient Group reported to smoke, on average, 20.26 cigarettes each day $(S E=1.27)$.

At both sites, the smoking cessation program consisted of a mixture of medical and cognitivebehavioral interventions. The time taken between the first test session and actual smoking cessation was 39.87 days ( $S E=6.26$ days). The second test session was completed between four and eight days after smoking cessation. In total, 37 participants did not complete the second test session. The sample size of the Patient Group at the second test session was thus 41. Participants dropped out from the study for various reasons. While some participants reported that they were simply unable to quit smoking, others did not return for the second test session because they were hospitalized or found it too time-consuming to participate. In most cases, however, participants simply stopped attending the smoking cessation sessions at some point in time without any explanation. In sum, the group of participants who dropped out from the study was quite heterogenic.

Within the final sample of 41 abstaining patients, relapse was assessed by means of a short telephone survey that was scheduled to take place 6 months after the second test session. Nevertheless, relapse data of two participants were obtained long after the anticipated follow-up period of 180 days had elapsed (i.e., 351 and 358 days vs. 188 days in the remaining sample), despite numerous attempts to contact these participants in due time. We therefore excluded the data of these participants from the 
analyses of the relapse data. Note, however, that none of the reported results are critically dependent upon on the inclusion or exclusion of these participants.

Participants in the Control Group had never smoked and were recruited from the network of acquaintances of two research assistants. They were not paid for their participation. The Patient Group and the Control Group were matched for age $\left(M_{\text {age }}=52.60\right.$ and $M_{\text {age }}=52.67$, respectively $)$, but not for other variables such as socioeconomic status. Some caution is thus in order when interpreting the results of between-groups comparisons. All participants gave their informed consent before participating. The study was approved by the Ethics Committees of Gent University Hospital and Gasthuisberg University Hospital.

\section{Apparatus and measures}

Apparatus. A standard portable computer was used to administer the implicit attitude measures. All stimuli were presented against a black background of an external LCD (19 inch, $1024 \times 768$ pixels). An Affect 4.0 program (Spruyt, Clarysse, Vansteenwegen, Baeyens, \& Hermans, 2010) controlled the presentation of the stimuli as well as the registration of the response latencies. An external voice key that was connected to the parallel port of the portable computer was used to measure response latencies during the EPT.

Evaluative Priming Task (EPT). In a typical evaluative priming task, participants are asked to respond to a series of target stimuli that have a clear evaluative meaning. Each target is preceded by a prime. If a particular person is faster to respond to positive target stimuli than to negative target stimuli after the presentation of a particular prime stimulus, one can infer that this person holds a positive implicit attitude towards this prime stimulus. Conversely, if a person is faster to respond to negative target stimuli as compared to positive target stimuli after the presentation of a particular prime stimulus, one can infer that this person holds a negative implicit attitude towards this prime stimulus (e.g., Fazio et al., 1995).

The stimuli that were used as primes in the present study were five pictures related to smoking (e.g., a person holding a cigarette), five pictures unrelated to smoking (e.g., a person holding a pencil), 
and five neutral stimuli (i.e., geometrical figures presented on a blue background). Target stimuli were five positive pictures (i.e., a baby, a bride, a dolphin, a kitten, and a teddy bear) and five negative pictures (i.e., a gun, a corpse, an explosion, a skull, and a bunch of worms). All pictures were 512 pixels wide and 384 pixels high. Target pictures were selected on the basis of norm data collected by Spruyt, Hermans, De Houwer, \& Eelen, 2002). The difference between the mean valence ratings of positive $(M=$ $3.37, S D=0.47)$ and negative target pictures $(M=-2.77, S D=0.83)$ was statistically reliable, $t(8)=12.05$, $p<.0001$. Following the procedures described by Spruyt, Hermans, De Houwer, Vandekerckhove, and Eelen (2007), participants were asked to name the target pictures as fast as possible with a single word (see also Vandromme, Hermans, \& Spruyt, 2011; Verhulst, Hermans, Baeyens, Spruyt, \& Eelen, 2006).

Each possible prime-target combination was presented once, resulting in 150 evaluative priming trials. Each trial started with a 500-ms presentation of a fixation cross. Next, after an inter-stimulus interval of $500 \mathrm{~ms}$, the prime was presented for $200 \mathrm{~ms}$. Finally, $50 \mathrm{~ms}$ after the offset of the prime, the target was presented until the participant gave a response, resulting in a Stimulus Onset Asynchrony (SOA) of $250 \mathrm{~ms}$. The experimenter coded whether the microphone was accurately triggered and whether the participant's response was correct by pressing one of three keys on the computer keyboard. After the experimenter entered the code, the next trial was initiated after a time interval that varied randomly between $500 \mathrm{~ms}$ and $1500 \mathrm{~ms}$.

Preceding the evaluative priming task, participants completed two series of practice trials. In the first practice phase, each target picture was presented once in a self-paced, random sequence (i.e., 10 trials). The correct naming response was presented underneath each target picture and participants were asked to memorize the pictures-word combinations. In the second practice phase, the target stimuli were again presented in a random sequence (i.e., 10 trials). Participants were asked to name the target pictures using the words that were learned during the first practice phase. Each target was presented until a naming response was registered.

Implicit Association Test (IAT). In a typical IAT, participants are asked to categorize stimuli into four different stimulus categories by pressing one of two response keys. The core idea underlying the 
IAT is that categorization performance should be better when categories that are associated in memory are assigned to the same response key. Hence, by examining which response assignments result in the best categorization performance, one can determine which stimulus categories are more closely associated in memory.

In the present study, the following categories were used: positive words (i.e., GOOD, HAPPY, PLEASANT, FRIENDLY, SYMPATHETIC), negative words (i.e., ANNOYING, CRUEL, ANGRY, FALSE, UNPLEASANT), pictures related to smoking, and pictures unrelated to smoking. The pictures used in the IAT were the same as those used in the EPT. All words were presented in white (font Arial, font size 28). Participants first completed two practice phases, one in which the words were to be categorized on the basis of their evaluative meaning (i.e., 20 trials, each stimulus presented twice), and one in which the pictures were to be categorized in terms of their relatedness to smoking (i.e., 20 trials, each stimulus presented twice). Whereas negative and positive stimuli were always assigned to the left and the right response key, respectively, response assignments were counterbalanced across participants for the pictorial stimuli. Half of the participants were asked to use the left and the right key to respond to smoking-related and smoking-unrelated pictures, respectively. The remaining participants were asked to use the reversed response assignment. Next, participants completed a first block of critical test trials in which all stimuli were presented three times (i.e., 60 trials in total). Participants were asked to use the same response assignments as those used in the preceding practice phases. Following the first test block, participants were again presented with a practice block in which smoking-related and smokingunrelated pictures were to be categorized in terms of their relatedness to smoking (i.e., 30 trials, each stimulus presented three times). Crucially, the response assignments were reversed. Finally, participants completed a second test block in which all stimuli were presented 3 times (i.e., 60 trials in total). The standard response assignment for the word stimuli was now combined with the reversed response assignment for the pictorial stimuli. In all phases, the relevant response labels were presented in the upper left and right corner of the computer screen (upper case, font Arial, font size 28). 
The specific version of the EPT that was used in the present research is known to be sensitive to variations in the extent to which participants adopt an explicit evaluative processing goal (Spruyt, 2014; Spruyt, De Houwer, Everaert, \& Hermans, 2012; Spruyt, De Houwer, \& Hermans, 2009; Spruyt, De Houwer, Hermans, \& Eelen, 2007). Therefore, given that the IAT involves explicit evaluative judgments, the EPT was always administered first. After completion of the EPT and the IAT, participants were asked to complete a series of self-report measures.

Self-report measures. The Fagerstrom Test for Nicotine Dependence (hereafter referred to as FTND) was used to measure nicotine dependency (Heatherton, Kozlowski, Frecker, \& Fagerstrom, 1991). The ACS was used to measure individual differences in the ability to focus perceptual attention, switch attention between tasks, and flexibly control thought (e.g., Derryberry \& Reed, 2002). The internal consistency of the ACS was acceptable (Cronbach's $\alpha=.77)$. On average, participants in the Patient Group ( $M=54.13$ ) exhibited the same degree of attentional control as participants in the Control Group $(M=52.57), t<1$. Finally, participants were asked to provide explicit valence ratings of cigarettes using two separate 10-point scales for pleasantness and unpleasantness. Each scale ranged from 1 ("not true") to 10 ("true"). For each participant, we subtracted the unpleasantness rating from the pleasantness rating to obtain a single explicit valence measure.

\section{Results}

\section{Data reduction}

For each participant and each test session, we calculated an implicit attitude score on the basis of the EPT data. In line with the procedures described by Spruyt, Hermans, De Houwer, Vandekerckhove, et al. (2007), we calculated two difference scores. First, we subtracted the mean response latencies observed on trials consisting of a smoking-related prime and a positive target from the mean response latencies observed on trials consisting of a smoking-related prime and a negative target. This difference score could, however, be biased by differences in the extent to which participants are generally faster or slower to respond to positive targets as compared to negative targets, irrespective of the nature of the preceding prime stimulus. We therefore calculated a second difference 
score by subtracting the mean response latencies observed on trials consisting of a neutral prime and a positive target from mean response latencies observed on trials consisting of a neutral prime and a negative target. Finally, the EPT score was obtained by subtracting the second difference score from the first difference score. The higher the EPT score, the more positive the implicit attitude towards smoking. Mean response latencies were computed after exclusion of trials on which an incorrect response (test session 1: $3.17 \%$, test session 2: $4.45 \%$ ), an erroneous voice key trigger (test session 1: $4.09 \%$, test session 2: $6.34 \%$ ), or a far-out value (test session 1: $7.50 \%$, test session 2: $5.38 \%$ ) was registered. Outliers were defined as response latencies that were smaller than $150 \mathrm{~ms}$ or larger than $1000 \mathrm{~ms}$ (Ratcliff, 1993). Prior to outlier exclusion, the overall mean response latency was 729 ms during the first test session. During the second test session, the overall mean response latency was $669 \mathrm{~ms}$.

Individual IAT scores were obtained using the D-600 scoring algorithm described by Greenwald, Nosek, and Banaji (2003). Accordingly, all trials with latencies larger than 10,000 ms were eliminated (test session 1: $0.28 \%$, test session 2: $0.08 \%$ ). The proportion of trials with a response latency below $300 \mathrm{~ms}$ was quite low (test session 1: $0.10 \%$, test session 2: $0.00 \%$ ) and never exceeded the $10-\%$ cutoff point for an individual participant. On average, it took participants $1147 \mathrm{~ms}$ to respond during the first test session. During the second test session, the overall mean response latency was $1037 \mathrm{~ms}$. The test block in which smoking-related stimuli and negative stimuli were assigned to the same key was defined as the incompatible block. The test block in which smoking-related stimuli and positive stimuli were assigned to the same key was defined as the compatible block. Positive IAT scores thus reflect a positive implicit attitude towards smoking.

\section{Attitudes at the group level: Differences between groups prior to smoking cessation}

We first examined the explicit attitude ratings. Whereas participants in the Control Group reported, on average, a strong negative attitude towards cigarettes, $M=-8.00, S D=2.21, t(29)=-19.80$, $p<.001$, participants in the Patient Group reported a mild (but non-significant) positive attitude towards 
cigarettes, $M=0.95, S D=5.01, t(77)=1.67, p=.10$. The difference between both groups was statistically reliable, $t(103.92)=12.85, p<.00001 .^{1}$

The results obtained with the EPT were more or less in line with this data pattern. Whereas participants in the Control Group exhibited a strong negative implicit attitude towards smoking, $M=-25$ $\mathrm{ms}, S D=44 \mathrm{~ms}, t(29)=3.05, p<.005$, participants in the Patient Group exhibited, on average, no implicit preference at all, $M=0 \mathrm{~ms}, S D=46 \mathrm{~ms}, t<1$. The difference between both groups was again reliable, $t(106)=2.49, p<.05$.

The results obtained with the IAT showed a completely different data pattern. The mean IAT score obtained in the Patient Group was significantly smaller than zero, $M=-.37, S D=.50, t(77)=-6.55$, $p<.00001$, suggesting a (strong) negative implicit attitude towards smoking. The mean IAT score obtained in the Control Group was also negative, albeit not significantly so, $M=-.15, S D=.58, t(29)=-$ 1.39, $p=.17$. In fact, the negative implicit attitude towards smoking as measured by the IAT was much more pronounced in the Patient Group as compared to the Control Group, $t(106)=2.00, p<.05$.

We also examined whether implicit and explicit attitudes towards smoking were different in patients who did $(n=37)$ and did not drop out $(n=41)$ before the second test session took place. Reassuringly, none of these comparisons approached significance, all $t s<1.04$, all $p s>.30$. Both groups of smokers were also comparable in terms of attentional control (ACS), daily cigarette consumption, and self-reported nicotine dependence (FTND), all $t s<1.37$, all $p s>.17$.

\section{Attitudes at the group level: Differences between test sessions}

Prior to smoking cessation, the mean explicit attitude towards cigarettes was mildly positive in participants who completed both test sessions, $M=1.17, S D=5.40, t(40)=1.39, p=.17$. After smoking cessation, the same group of participants reported a strong negative attitude towards cigarettes, $M=-$ $2.97, S D=5.40, t(40)=-3.53, p<.005$. The difference between both test sessions was highly significant, $t(40)=5.44, p<.001$.

\footnotetext{
${ }^{1}$ The Welch-Satterthwaite approximation method was used to compensate for the violation of the equality-ofvariances assumption.
} 
In line with this observation, the IAT data also suggest that smoke-related cues became more negative from the first to the second test session. Participants who completed both test sessions displayed a strong negative IAT score prior to smoking cessation, $M=-.43, S D=.40, t(40)=6.79, p<$ .001 , that became even more negative after smoking cessation, $M=-.54, S D=.54, t(40)=6.36, p<.001$. However, the difference between both test sessions was far from significant, $t(40)=1.32, p=.20$. In contrast, there was no evidence whatsoever that implicit attitudes towards smoking as measured by the EPT changed over time. Both at the first ( $M=3 \mathrm{~ms}, S D=44 \mathrm{~ms}$ ) and the second test session $(M=1 \mathrm{~ms}, S D=39 \mathrm{~ms})$ the mean EPT score was virtually zero, $t<1$.

Attitudes at the individual level: Correlations between different measures, test-retest reliabilities, and internal consistencies.

Both prior to smoking cessation (test session 1 ) and after smoking cessation (test session 2), all correlations between the explicit attitude measure, the EPT, and the IAT were non-significant (see Table 1). Nevertheless, significant test - retest correlations were obtained for both IAT and the explicit attitude measure. The test - retest correlation of the EPT was unreliable. Finally, we examined the internal consistency of the two implicit attitude measures. In line with earlier reports (e.g., Greenwald \& Nosek, 2001), internal consistency of the IAT was quite high, both at the first test session (Cronbach's $\alpha$ $=.87$ ) and the second test session (Cronbach's $\alpha=.89$ ). Also in line with earlier reports (e.g., Bosson, Swann, \& Pennebaker, 2000), the internal consistency of EPT was considerably lower. For the first test session, the internal consistency of the EPT was still acceptable (i.e., Cronbach's $\alpha=.75$ ). For the second test session, however, the internal consistency of the EPT was substandard (Cronbach's $\alpha=.18)^{2}$

\footnotetext{
${ }^{2}$ For the IAT, Cronbach $\alpha$ 's were computed on the basis of five different IAT scores. In line with earlier work by Teige-Mocigemba, Klauer, and Rothermund (2008), each test block was divided into five sequential sub-blocks and an IAT score was computed for each pair of sub-blocks. Cronbach $\alpha$ 's for the EPT were also computed on the basis of five different EPT scores, one for each smoke-related prime stimulus. Each of these EPT scores was computed as described in the Data reduction section, with the exception that we only included smoke-related trials on which a specific smoke-related stimulus was presented.
} 


\section{Attitudes and behavior: Relationship between attitude measures obtained prior to smoking cessation (test session 1), smoking behavior, and relapse}

We first examined whether the (implicit and explicit) attitude measures correlated with (a) selfreported smoking behavior (i.e., daily cigarette consumption), (b) nicotine dependency (i.e., FTND), and (c) the time taken to quit smoking. As can be seen in Table 2, both the explicit attitude measure and the IAT failed to correlate with each of these behavioral measures. In contrast, the EPT scores correlated positively with self-reported nicotine dependence as well as the number of cigarettes that participants reported smoking each day. The correlation between the EPT scores and the number of days taken to quit smoking was not significant.

Next, we examined the extent to which the attitude measures were related to relapse. In total, 18 patients (46.15\%) relapsed within 6 months. Univariate logistic regression analyses revealed no evidence whatsoever for the existence of a meaningful relationship between relapse and individual differences in the self-reported attitude towards cigarettes, $\chi^{2}<1$ (56.4\% correct classifications). Likewise, relapse was unrelated to individual differences in the implicit attitude towards smoking as measured by the IAT, $\chi^{2}<1$ (56.4\% correct classifications). A significant relationship was found, however, between relapse and individual differences in the implicit attitude towards smoking as measured by the EPT, $\chi^{2}(1)=4.59, p<.05$, Nagelkerke $R^{2}=.15, O R=1.018(69.2 \%$ correct classifications). The more positive the EPT score, the higher the chance to relapse within 6 months. In line with this observation, the mean EPT score obtained in patients who relapsed ( $M=21 \mathrm{~ms}$ ) was clearly different from the mean EPT score obtained in patients who remained abstinent $(M=-9 \mathrm{~ms})$, $t(37)=2.13, p<.05$.

To examine whether the EPT scores were predictive of relapse over and above other predictors, we first examined whether relapse was related to age, gender, self-reported nicotine dependence (i.e., FTND score), daily cigarette consumption, and the time needed to actually quit smoking. Only one of these variables proved to be a valid predictor of relapse, i.e. the time needed to actually quit smoking, $\chi^{2}(1)=7.96, p<.01$, Nagelkerke $R^{2}=.25, O R=1.030$ (66.7\% correct classifications). The predictive 
validity of all the other variables was far from significant $\left(\chi^{2} s<1.25, p s>.27\right)$. Next, we examined whether the EPT scores were predictive of relapse over and above the time needed to actually quit smoking. Adding the EPT scores as a predictor, resulted in a significantly better model fit, $\chi^{2}(1)=5.00, p$ $<.05$, Nagelkerke $R^{2}=.38, O R=1.021$. On the basis of this model, $71.8 \%$ of all cases were classified correctly.

Finally, we examined whether the predictive validity of the implicit attitude measures was dependent upon attentional control (ACS). To that end, we performed two additional logistic regression analyses, one for the IAT and one for the EPT, in which the implicit attitude measure, the (continuous) ACS scores, and the interaction term were used as predictors. For the EPT data, the interaction term was reliable, Wald $=4.09, p<.05, O R=.995$. In line with our expectations, follow-up analyses confirmed that the EPT scores were predictive of relapse in participants low in attentional control (i.e., ACS score $\leq 56, n$ $=20), \chi^{2}(1)=6.49, p<.05$, Nagelkerke $R^{2}=.41$ (90.0\% correct classifications). In contrast, participants high in attentional control (i.e., ACS score $>56, n=19$ ) exhibited no evidence whatsoever for the existence of a meaningful relationship between the EPT scores and relapse, $\chi^{2}<1(63.2 \%$ correct classifications). A similar analysis for the IAT data confirmed that the IAT scores were unrelated to relapse, both in participants who exhibited a high degree of attentional control, $\chi^{2}<1$, and in participants who exhibited a low degree of attentional control, $\chi^{2}<1$. Accordingly, the interaction between the ACS scores and the IAT was far from significant, Wald $=1.48, p>.22$. The correlation between the ACS and the implicit attitude measures was unreliable at both test moments (all $|r|<.15$, all $p>$.23).

\section{Attitudes and behavior: Relationship between attitude measures obtained after smoking cessation (test session 2), smoking behavior, and relapse}

All the analyses reported above were repeated using the attitudes measures obtained after smoking cessation. As can be seen in Table 2, none of the correlations between the attitude measures and (various aspects of) smoking behavior was statistically reliable. Likewise, none of the attitude measures was related to relapse. Virtually all effects involving either the EPT or the IAT were associated 
with a Wald statistic smaller than 1.32 ( $p s>.25$ ). The only exception was the interaction between the IAT and the (continuous) ACS scores, Wald $=3.83, p=.05, O R=.788$. Follow-up analyses revealed, however, that the relationship between the IAT and relapse was unreliable both in participants high in attentional control, Wald $=1.38, p=.24, O R=.255$, and in participants low in attentional control, Wald $<$

1. We are therefore reluctant to give much weight to this isolated finding.

\section{Attitudes and behavior: Relationship between relapse and changes in attitude measures}

Finally, we examined whether relapse was dependent upon the extent to which implicit and explicit attitudes towards smoking-related cues changed from the first to the second test session. Both for the explicit attitude ratings and the IAT scores, this relationship was unreliable, both $\chi^{2} s<1$. In contrast, changes in the EPT scores did correlate with relapse, $\chi^{2}(1)=4.04, p<.05$, Nagelkerke $R^{2}=.13$, $O R=1.011$ (71.8 \% correct classifications). In all likelihood, however, this finding resulted from the fact that (a) the EPT scores obtained at the first test session were reliable and related to relapse whereas (b) the EPT scores obtained at the second test session were completely unreliable (see above). We are therefore reluctant to give much weight to this to this finding.

\section{Discussion}

In line with two-process models of addiction (e.g., Deutsch \& Strack, 2006; Strack \& Deutsch, 2004; Wiers \& Stracy, 2006), there is now ample evidence showing that automatic processes play a critical role in addiction. Substance-related stimuli have been shown to automatically (a) grab the user's attention (e.g., Field \& Cox, 2008), (b) activate approach/avoidance tendencies (e.g., Eberl et al., 2013; Spruyt et al., 2013; Wiers, Eberl, Rinck, Becker, \& Lindenmeyer, 2011), and (c) activate implicit attitudes from memory (e.g., Houben, Schoenmakers, \& Wiers, 2010; Wiers et al., 2002). Nevertheless, only a limited number of studies have documented the extent to which these automatic processes drive relapse in abstaining patients.

In the present study, we examined whether implicit attitude measures as measured by the IAT and the EPT can be used to predict long-term relapse in abstaining nicotine-dependent patients. Our findings clearly indicate that implicit attitude scores obtained with (an adapted version of) the EPT (see 
Spruyt, Hermans, De Houwer, Vandekerckhove, et al., 2007) are indeed predictive of relapse over a 6month follow-up period. In line with our expectations, relapse rates were higher among participants who, prior to smoking cessation, exhibited a more positive implicit attitude towards smoking as compared to participants who exhibited a more negative implicit attitude towards smoking. Moreover, the EPT scores were found to predict relapse over and above other predictors such as the time take to quit smoking, daily cigarette consumption, etc. Taken together, these findings strongly suggest that the EPT can be used as a unique and powerful tool to predict addictive behavior, a conclusion that is further corroborated by two additional observations. First, the EPT scores were found to correlate with nicotine dependence (FTND) as well as daily cigarette consumption. Second, the EPT scores also discriminated between smokers and non-smokers: In line with earlier reports (e.g., Payne et al., 2007), the mean EPT score was significantly more negative in the Control Group than in the Patient Group.

Interestingly, the observed relationship between the EPT scores obtained prior to smoking cessation and relapse was contingent upon participants' level of attentional control. That is, the predictive validity of the EPT scores was much more pronounced in participants who exhibited a low degree of attentional control (i.e., $90.0 \%$ correct classifications) as compared to participants who exhibited a high degree of attentional control (i.e., $63.2 \%$ correct classifications). This data pattern is clearly in line with the idea that implicit attitudes towards drug-related cues are more likely to affect addictive behavior in participants who have difficulty controlling the attention-grabbing power of smoking-related stimuli (Farris et al., 2010; Wiers et al., 2010). It might thus be worthwhile to develop intervention strategies that target an individual's level of attentional control rather than his/her implicit attitudes towards drug-related cues per se. As an alternative explanation, however, it might also be argued that the EPT is simply unable to capture implicit attitudes in participants who are characterized by a high degree of attentional control. Irrespectively, the observation that the predictive validity of the EPT was contingent upon attentional control suggests that measures of attentional control may be used to identify individuals for whom the EPT data are likely to predict behavior. Put differently, it may be possible to discriminate between individuals for whom the task 'works' and individuals for whom the 
task 'doesn't work'. Given that the overall predictive validity of the EPT is still far from perfect, such an approach seems particularly fruitful from an applied point of view.

It should be noted, however, that the predictive validity of the EPT scores was confined to data that were gathered prior to smoking cessation. An analysis of the internal consistency of the EPT scores suggests at least one explanation for this finding. Whereas the internal consistency of the EPT was quite good for data collected during the first test session (Cronbach's $\alpha=.75$ ), it was simply substandard for data collected during the second test session (Cronbach's $\alpha=.18$ ). For the same reason, it is also difficult to interpret the observations that (a) the EPT scores did not change from the first to the second test session, and (b) that the EPT scores obtained after smoking cessation were unrelated to (various aspects of) smoking behavior. Very little is known, however, about the extent to which prior experience with the EPT can affect task performance in subsequent test sessions. Additional research would therefore be needed to explain why exactly the reliability of the EPT scores dropped from the first to the second test session.

A final point of discussion concerns the results obtained with the IAT. Unlike Marhe et al. (2013), we found no evidence for the existence of a meaningful relationship between implicit attitudes as measured by the IAT and relapse. The IAT scores also failed to correlate with other (behavioral) measures of nicotine addiction. This discrepancy can be accounted for in a number of ways. First, whereas Marhe et al. (2013) looked at relapse within a window of just 9 days, the follow-up period in the present study spanned (about) 6 months. It could thus be hypothesized that a significant relationship between the IAT scores and relapse may have been found had we assessed relapse at an earlier time. Second, and probably more importantly, Marhe et al. (2013) reported that their IAT measure was predictive of relapse only when the IAT was administered during an episode of increased temptation. In our study, however, participants were always tested at predetermined moments. It was thus a matter of chance whether participants experienced increased temptation at the time of testing. If this is a prerequisite for to IAT to produce valid implicit attitude scores in the context of addiction, the null-findings that were obtained with the IAT are anything but surprising. Finally, it might simply be 
argued that the poor (predictive) validity of the IAT scores resulted from the fact that the IAT was always administered after participants had already completed the EPT. As explained above, we deliberately opted for strategy because the specific version of the EPT that was used in the present research is known to be sensitive to variations in the extent to which participants adopt an explicit evaluative processing goal. Therefore, given that the IAT involves explicit evaluative judgments, we had no other option but to use a fixed task order. As a consequence, however, one might argue that participants were already fatigued or bored by the time they were asked to complete the IAT.

Still, it remains a remarkable observation that we failed to predict behavior on the basis of the IAT scores whilst their reliability was more than acceptable. In this respect, it is important to emphasize that the IAT revealed a strong negative attitude towards smoking in the Patient Group. In fact, the negative implicit attitude towards smoking as measured by the IAT (a) was more pronounced in the Patient Group than in the Control Group and (b) even tended to become more negative from the first to the second test session. While the interpretation of the latter finding is complicated by the fact that a proper control condition is missing, these observations seem to suggest that the IAT was either influenced by automatically activated extra-personal associations (i.e., knowledge about the fact that smoking is generally viewed as negative in Western societies; see Karpinski \& Hilton, 2001) or by automatically activated (but personally endorsed) propositional knowledge about the negative consequences of smoking (see Hughes, Barnes-Holmes, \& De Houwer, 2011). Interestingly, this interpretation would coincide with findings obtained by Chassin, Presson, Sherman, Seo, and Macy (2010). In line with our observations, these authors found the average IAT score in smokers to be negative rather than positive (see also Swanson et al., 2001). Moreover, Chassin et al. (2010) observed that smokers were more likely to quit smoking as the IAT revealed a more negative attitude towards smoking. Given that attempts to quit smoking must be driven by personally endorsed health concerns and (negative) societal views of smoking behavior, it seems logical that an implicit measure that captures this type of information can be used to predict smoking cessation attempts. At the same time, however, our findings indicate that such a measure may be unsuited to predict relapse in smokers who 
do manage to quit smoking. For that purpose, the EPT is clearly better suited. It should be noted, however, that new variants of the IAT have been developed that are known to control for the influence of factors such as extra-personal associations (e.g., the personalized IAT; see Olson \& Fazio, 2004). It could thus be worthwhile to examine the predictive validity of these new generation of IAT measures in future addiction research.

In sum, the present findings strongly suggest that implicit attitudes towards drug-related cues are critically involved in long-term relapse. It thus seems worthwhile (a) to take these implicit attitudes into account when trying to predict relapse and (b) to further scrutinize the usefulness of treatment strategies that target these implicit attitudes directly (e.g., Houben, Havermans, \& Wiers, 2010). 


\section{References}

Bosson, J. K., Swann, W. B., \& Pennebaker, J. W. (2000). Stalking the perfect measure of implicit selfesteem: The blind men and the elephant revisited? Journal of Personality and Social Psychology, 79, 631-643. DOI 10.1037//0022-3514.79.4.631

Chassin, L., Presson, C. C., Sherman, S. J., Seo, D. C., \& Macy, J. T. (2010). Implicit and explicit attitudes predict smoking cessation: Moderating effects of experienced failure to control smoking and plans to quit. Psychology of Addictive Behaviors, 24, 670-679. DOI 10.1037/A0021722

Conrey, F. R., Sherman, J. W., Gawronski, B., Hugenberg, K., \& Groom, C. J. (2005). Separating multiple processes in implicit social cognition: The quad model of implicit task performance. Journal of Personality and Social Psychology, 89, 469-487. DOI 10.1037/0022-3514.89.4.469

De Houwer, J., Teige-Mocigemba, S., Spruyt, A., \& Moors, A. (2009). Implicit measures: A normative analysis and review. Psychological Bulletin, 135, 347-368. DOI 10.1037/A0014211

Derryberry, D. (2002). Attention and voluntary self-control. Self and Identity, 1, 105-111. DOI $10.1080 / 152988602317319276$

Derryberry, D., \& Reed, M. A. (2002). Anxiety-related attentional biases and their regulation by attentional control. Journal of Abnormal Psychology, 111, 225-236. DOI 10.1037//0021$843 \times .111 .2 .225$

Descheemaeker, M., Spruyt, A., \& Hermans, D. (2014). On the relationship between the indirectly measured attitude towards beer and beer consumption: The role of attitude accessibility. Plos One, 9, e95302. DOI 10.1371/journal.pone.0095302

Deutsch, R., \& Strack, F. (2006). Impulsive and reflective determinants of addictive behavior. In R. W. Wiers \& A. W. Stacy (Eds.), Handbook of implicit cognition and addiction (pp. 45-57). Thousand Oaks, CA: SAGE. 
Eberl, C., Wiers, R. W., Pawelczack, S., Rinck, M., Becker, E. S., \& Lindenmeyer, J. (2013). Approach bias modification in alcohol dependence: Do clinical effects replicate and for whom does it work best? Developmental Cognitive Neuroscience, 4, 38-51. DOI 10.1016/j.dcn.2012.11.002

Fadardi, J. S., \& Cox, W. M. (2009). Reversing the sequence: Reducing alcohol consumption by overcoming alcohol attentional bias. Drug and Alcohol Dependence, 101, 137-145. DOI 10.1016/j.drugalcdep.2008.11.015

Farris, S. R., Ostafin, B. D., \& Palfai, T. P. (2010). Distractibility moderates the relation between automatic alcohol motivation and drinking behavior. Psychology of Addictive Behaviors, 24, 151156. DOI 10.1037/A0018294

Fazio, R. H., Jackson, J. R., Dunton, B. C., \& Williams, C. J. (1995). Variability in automatic activation as an unobtrusive measure of racial-attitudes: A bona-fide pipeline? Journal of Personality and Social Psychology, 69, 1013-1027. DOI 10.1037//0022-3514.69.6.1013

Fazio, R. H., \& Towles-Schwen, T. (1999). The MODE model of attitude-behavior processes. In S. Chaiken \& Y. Trope (Eds.), Dual process theories in social psychology (pp. 97-116). New York: Guilford.

Field, M., \& Cox, W. M. (2008). Attentional bias in addictive behaviors: A review of its development, causes, and consequences. Drug and Alcohol Dependence, 97, 1-20. DOI 10.1016/j.drugalcdep.2008.03.030

Fox, H. C., Bergquist, K. L., Gu, P. H., \& Sinha, R. (2010). Interactive effects of cumulative stress and impulsivity on alcohol consumption. Alcoholism-Clinical and Experimental Research, 34, 13761385. DOI 10.1111/j.1530-0277.2010.01221.x

Gossop, M., Stewart, D., Browne, N., \& Marsden, J. (2002). Factors associated with abstinence, lapse or relapse to heroin use after residential treatment: protective effect of coping responses. Addiction, 97, 1259-1267. DOI 10.1046/j.1360-0443.2002.00227.x 
Greenwald, A. G., McGhee, D. E., \& Schwartz, J. L. K. (1998). Measuring individual differences in implicit cognition: The implicit association test. Journal of Personality and Social Psychology, 74, 14641480. DOI 10.1037/0022-3514.74.6.1464

Greenwald, A. G., \& Nosek, B. A. (2001). Health of the implicit association test at age 3. Zeitschrift Fur Experimentelle Psychologie, 48, 85-93

Greenwald, A. G., Nosek, B. A., \& Banaji, M. R. (2003). Understanding and using the implicit association test: I. An improved scoring algorithm. Journal of Personality and Social Psychology, 85, 197-216. DOI 10.1037/0022-3514.85.2.197

Heatherton, T. F., Kozlowski, L. T., Frecker, R. C., \& Fagerstrom, K. O. (1991). The fagerstrom test for nicotine dependence: A revision of the fagerstrom tolerance questionnaire. British Journal of Addiction, 86, 1119-1127

Houben, K., Havermans, R. C., \& Wiers, R. W. (2010). Learning to dislike alcohol: conditioning negative implicit attitudes toward alcohol and its effect on drinking behavior. Psychopharmacology, 211, 79-86. DOI 10.1007/s00213-010-1872-1

Houben, K., Nosek, B. A., \& Wiers, R. W. (2010). Seeing the forest through the trees: A comparison of different IAT variants measuring implicit alcohol associations. Drug and Alcohol Dependence, 106, 204-211. DOI 10.1016/j.drugalcdep.2009.08.016

Houben, K., Schoenmakers, T. M., \& Wiers, R. W. (2010). I didn't feel like drinking but I don't know why: The effects of evaluative conditioning on alcohol-related attitudes, craving and behavior. Addictive Behaviors, 35, 1161-1163. DOI 10.1016/j.addbeh.2010.08.012

Hughes, S., Barnes-Holmes, D., \& De Houwer, J. (2011). The dominance of associative theorizing in implicit attitude research: Propositional and behavioral alternatives. Psychological Record, 61, 465-496 
Karpinski, A., \& Hilton, J. L. (2001). Attitudes and the implicit association test. Journal of Personality and Social Psychology, 81, 774-788. DOI 10.1037//0022-3514.81.5.774

Klauer, K. C., Voss, A., Schmitz, F., \& Teige-Mocigemba, S. (2007). Process components of the implicit association test: A diffusion-model analysis. Journal of Personality and Social Psychology, 93, 353-368. DOI 10.1037/0022-3514.93.3.353

Lindgren, K. P., Neighbors, C., Westgate, E., \& Salemink, E. (2014). Self-control and implicit drinking identity as predictors of alcohol consumption, problems, and cravings. Journal of Studies on Alcohol and Drugs, 75, 290-298

Marhe, R., Waters, A. J., van de Wetering, B. J. M., \& Franken, I. H. A. (2013). Implicit and explicit drugrelated cognitions during detoxification treatment are associated with drug relapse: An ecological momentary assessment study. Journal of Consulting and Clinical Psychology, 81, 1-12. DOI 10.1037/A0030754

Moos, R. H., \& Moos, B. S. (2006). Rates and predictors of relapse after natural and treated remission from alcohol use disorders. Addiction, 101, 212-222. DOI 10.1111/j.1360-0443.2006.01310.x

Noel, X., Colmant, M., Van der Linden, M., Bechara, A., Bullens, Q., Hanak, C., \& Verbanck, P. (2006). Time course of attention for alcohol cues in abstinent alcoholic patients: The role of initial orienting. Alcoholism-Clinical and Experimental Research, 30, 1871-1877. DOI 10.1111/j.15300277.00224.x

Olson, M. A., \& Fazio, R. H. (2004). Reducing the influence of extrapersonal associations on the implicit association test: Personalizing the IAT. Journal of Personality and Social Psychology, 86, 653-667. DOI 10.1037/0022-3514.86.5.653

Patterson, F., Jepson, C., Loughead, J., Perkins, K., Strasser, A. A., Siegel, S., . . Lerman, C. (2010). Working memory deficits predict short-term smoking resumption following brief abstinence. Drug and Alcohol Dependence, 106, 61-64. DOI 10.1016/j.drugalcdep.2009.07.020 
Payne, B. K., McClernon, F. J., \& Dobbins, I. G. (2007). Automatic affective responses to smoking cues. Experimental and Clinical Psychopharmacology, 15, 400-409. DOI 10.1037/1064-1297.15.4.400

Pieters, S., Burk, W. J., Van der Vorst, H., Wiers, R. W., \& Engels, R. C. M. E. (2012). The moderating role of working memory capacity and alcohol-specific rule-setting on the relation between approach tendencies and alcohol use in young adolescents. Alcoholism: Clinical and Experimental Research, 36, 915-922. DOI 10.1111/j.1530-0277.2011.01688.x

Powell, J., Dawkins, L., West, R., Powell, J., \& Pickering, A. (2010). Relapse to smoking during unaided cessation: clinical, cognitive and motivational predictors. Psychopharmacology, 212, 537-549. DOI 10.1007/s00213-010-1975-8

Ratcliff, R. (1993). Methods for dealing with reaction-time outliers. Psychological Bulletin, 114, 510-532. DOI 10.1037/0033-2909.114.3.510

Rooke, S. E., Hine, D. W., \& Thorsteinsson, E. B. (2008). Implicit cognition and substance use: A metaanalysis. Addictive Behaviors, 33, 1314-1328. DOI 10.1016/j.addbeh.2008.06.009

Rothermund, K., Teige-Mocigemba, S., Gast, A., \& Wentura, D. (2009). Minimizing the influence of recoding in the Implicit Association Test: The Recoding-Free Implicit Association Test (IAT-RF). Quarterly Journal of Experimental Psychology, 62, 84-98. Doi 10.1080/17470210701822975

Rothermund, K., \& Wentura, D. (2004). Underlying processes in the implicit association test: Dissociating salience from associations. Journal of Experimental Psychology-General, 133, 139-165. DOI 10.1037/0096-3445.133.2.139

Sheffer, C., MacKillop, J., McGeary, J., Landes, R., Carter, L., Yi, R., . . Bickel, W. (2012). Delay discounting, locus of control, and cognitive impulsiveness independently predict tobacco dependence treatment outcomes in a highly dependent, lower socioeconomic group of smokers. American Journal on Addictions, 21, 221-232. DOI 10.1111/j.1521-0391.2012.00224.x 
Spruyt, A. (2014). Attention please: Evaluative priming effects in a valent/non-valent categorisation task (reply to Werner \& Rothermund, 2013). Cognition \& Emotion, 28, 560-569. DOI $10.1080 / 02699931.2013 .832653$

Spruyt, A., Clarysse, J., Vansteenwegen, D., Baeyens, F., \& Hermans, D. (2010). Affect 4.0 a free software package for implementing psychological and psychophysiological experiments. Experimental Psychology, 57, 36-45. DOI 10.1027/1618-3169/A000005

Spruyt, A., De Houwer, J., Everaert, T., \& Hermans, D. (2012). Unconscious semantic activation depends on feature-specific attention allocation. Cognition, 122, 91-95. DOI 10.1016/j.cognition.2011.08.017

Spruyt, A., De Houwer, J., \& Hermans, D. (2009). Modulation of automatic semantic priming by featurespecific attention allocation. Journal of Memory and Language, 61, 37-54. DOI 10.1016/j.jml.2009.03.004

Spruyt, A., De Houwer, J., Hermans, D., \& Eelen, P. (2007). Affective priming of nonaffective semantic categorization responses. Experimental Psychology, 54, 44-53. DOI 10.1027/1618-3169.54.1.44

Spruyt, A., De Houwer, J., Tibboel, H., Verschuere, B., Crombez, G., Verbanck, P., . . Noel, X. (2013). On the predictive validity of automatically activated approach/avoidance tendencies in abstaining alcohol-dependent patients. Drug and Alcohol Dependence, 127, 81-86. DOI 10.1016/j.drugalcdep.2012.06.019

Spruyt, A., Hermans, D., De Houwer, J., \& Eelen, P. (2002). On the nature of the affective priming effect: Affective priming of naming responses. Social Cognition, 20, 227-256. DOI 10.1521/soco.20.3.227.21106

Spruyt, A., Hermans, D., De Houwer, J., Vandekerckhove, J., \& Eelen, P. (2007). On the predictive validity of indirect attitude measures: Prediction of consumer choice behavior on the basis of affective 
priming in the picture-picture naming task. Journal of Experimental Social Psychology, 43, 599610. DOI 10.1016/j.jesp.2006.06.009

Spruyt, A., Hermans, D., De Houwer, J., Vandromme, H., \& Eelen, P. (2007). On the nature of the affective priming effect: Effects of stimulus onset asynchrony and congruency proportion in naming and evaluative categorization. Memory \& Cognition, 35, 95-106. DOI 10.3758/Bf03195946

Strack, F., \& Deutsch, R. (2004). Reflective and impulsive determinants of social behavior. Personality and Social Psychology Review, 8, 220-247. DOI 10.1207/s15327957pspr0803_1

Swanson, J. E., Rudman, L. A., \& Greenwald, A. G. (2001). Using the Implicit Association Test to investigate attitude-behaviour consistency for stigmatised behaviour. Cognition \& Emotion, 15, 207-230. DOI 10.1080/0269993004200060

Teige-Mocigemba, S., Klauer, K. C., \& Rothermund, K. (2008). Minimizing Method-Specific Variance in the IAT A Single Block IAT. European Journal of Psychological Assessment, 24, 237-245. DOI $10.1027 / 1015-5759.24 .4 .237$

Thush, C., Wiers, R. W., Ames, S. L., Grenard, J. L., Sussman, S., \& Stacy, A. W. (2008). Interactions between implicit and explicit cognition and working memory capacity in the prediction of alcohol use in at-risk adolescents. Drug and Alcohol Dependence, 94, 116-124. DOI 10.1016/j.drugalcdep.2007.10.019

Townshend, J. M., \& Duka, T. (2001). Attentional bias associated with alcohol cues: differences between heavy and occasional social drinkers. Psychopharmacology, 157, 67-74

Vandromme, H., Hermans, D., \& Spruyt, A. (2011). Indirectly Measured Self-esteem Predicts Gaze Avoidance. Self and Identity, 10, 32-43. DOI 10.1080/15298860903512149 
Verhulst, F., Hermans, D., Baeyens, F., Spruyt, A., \& Eelen, P. (2006). Determinants and predictive validity of direct and indirect measures of recently acquired food attitudes. Appetite, 46, 137143. DOI 10.1016/j.appet.2005.11.004

Wiers, R. W., Ames, S. L., Hofmann, W., Krank, M., \& Stacy, A. W. (2010). Impulsivity, impulsive and reflective processes and the development of alcohol use and misuse in adolescents and young adults. Frontiers in Psychology, 1, 144. DOI 10.3389/Fpsyg.2010.00144

Wiers, R. W., Eberl, C., Rinck, M., Becker, E. S., \& Lindenmeyer, J. (2011). Retraining automatic action tendencies changes alcoholic patients' approach bias for alcohol and improves treatment outcome. Psychological Science, 22, 490-497. DOI 10.1177/0956797611400615

Wiers, R. W., \& Stracy, A. W. (2006). Handbook of implicit cognition and addiction. Thousand Oaks, CA: SAGE.

Wiers, R. W., van Woerden, N., Smulders, F. T. Y., \& de Jong, P. J. (2002). Implicit and explicit alcoholrelated cognitions in heavy and light drinkers. Journal of Abnormal Psychology, 111, 648-658. DOI 10.1037//0021-843x.111.4.648

Wise, R. A. (1988). The neurobiology of craving: Implications for the understanding and treatment of addiction. Journal of Abnormal Psychology, 97, 118-132. DOI 10.1037/0021-843x.97.2.118 


\section{Author Note}

Correspondence concerning this article should be addressed to Adriaan Spruyt, Department of Psychology, Ghent University, H. Dunantlaan 2, B-9000 Ghent, Belgium. Electronic mail may be sent to Adriaan.Spruyt@UGent.be. Preparation of this paper was supported by Grant BOF/GOA2006/001 and Methusalem Grant BOF09/01M00209 of Ghent University. Bram Van Bockstaele is funded by a FMGUvA Research Priority Grant on Affect Regulation. Adriaan Spruyt is Postdoctoral Fellow of the Flemish Research Foundation (FWO - Vlaanderen). The authors would like to thank Diederik Derijcke, Lene Rutten, and Jeffrey De Winne for their help in collecting the data. 
TABLE 1

Attitude measures: Correlations and test - retest reliability

\begin{tabular}{|c|c|c|c|c|c|c|c|}
\hline \multirow[b]{2}{*}{ Attitude measure } & \multicolumn{3}{|c|}{ prior to smoking cessation } & \multicolumn{3}{|c|}{ after smoking cessation } & \multirow[b]{2}{*}{ test - retest } \\
\hline & 1 & 2 & 3 & 1 & 2 & 3 & \\
\hline 1. Explicit Attitude & 1 & & & 1 & & & $.59 * *$ \\
\hline 2. Evaluative Priming Task & .03 & 1 & & .10 & 1 & & -.25 \\
\hline 3. Implicit Association Test & -.15 & .07 & 1 & -.14 & -.03 & 1 & $.40^{*}$ \\
\hline
\end{tabular}

$* p<.01, * * p<.001$ 
TABLE 2

Correlations between smoking behavior and attitude measures

\begin{tabular}{|c|c|c|c|}
\hline Attitude Measure & nicotine dependence & \# cigarettes & \# days \\
\hline \multicolumn{4}{|c|}{ Attitude measures obtained prior to smoking cessation $(N=78)$} \\
\hline Explicit Attitude & .14 & .07 & .21 \\
\hline Evaluative Priming Task & $.26^{*}$ & $.34^{* *}$ & .03 \\
\hline Implicit Association Test & .08 & -.10 & .12 \\
\hline \multicolumn{4}{|c|}{ Attitude measures obtained after smoking cessation $(N=41)$} \\
\hline Explicit Attitude & -.11 & -.13 & .20 \\
\hline Evaluative Priming Task & .07 & .04 & .01 \\
\hline Implicit Association Test & -.13 & $-.27 \dagger$ & -.05 \\
\hline
\end{tabular}

\# cigarettes: daily cigarette consumption; \# days: number of days between the start of the smoking cessation program and actual smoking cessation: ${ }^{* *} p<.005,{ }^{*} p<.05,+p<.10$ 